Original Research Paper

\title{
Pelatihan Penggunaan Aplikasi SIPGAR Bagi Pemuda DAS di Kota Palangka Raya
}

\author{
Yudo Harvianto $^{1}$, Andi Tenri Abeng ${ }^{1}$, Garry William Dony ${ }^{1}$, Abdullah ${ }^{1}$, Muharfa $^{1}$ \\ ${ }^{1-5}$ Pendidikan Jasmani, Kesehatan dan Rekreasi, Universitas Palangka Raya, Palangka Raya, Indonesia
}

https://doi.org/10.29303/jpmpi.v3i2.1056

Sitasi: Harvianto, Y., Abeng, A. T., Dony, G. W., Abdullah \& Murharfa. (2021). Workshop Penyusunan Pedoman Pembelajaran Blended di SMA Swasta Kecamatan Narmada Lombok Barat. Jurnal Pengabdian Magister Pendidikan IPA 4(4)

\author{
Article history \\ Received: 02 Oktober 2021 \\ Revised: 20 Oktober 2021 \\ Accepted: 07 November 2021 \\ *Corresponding Author: Yudo \\ Harvianto, Pendidikan \\ Jasmani, Kesehatan dan \\ Rekreasi, Universitas Palangka \\ Raya, Palangka Raya, \\ Indonesia; \\ Email: yudo@fkip.upr.ac.id
}

\begin{abstract}
During the Covid-19 pandemic, health factors in the form of maintaining physical fitness are very important. There are many ways to keep your body in shape. The most effective way to maintain physical fitness during the current covid-19 pandemic is to comply with health protocols and get used to exercising so that the body is always in a fit condition. Exercise can be used as an alternative to keep the body fit. Another important thing besides exercising during the current pandemic is checking physical fitness regularly and independently. One way that can be used is the SIPGAR application. An application published by the Ministry of Health of the Republic of Indonesia to check a person's physical fitness independently via Android. The purpose of this activity is that participants get education about physical fitness and can do tests independently through the operation of the SIPGAR application. The method used in this activity is training. The training was conducted for 5 times, with different participants and places. The total number of participants who attended the training was 42 people. Based on the results of the training, there were several problems experienced by the participants including not all participants were able to download applications on the play store and register an account. This is because each participant's cellphone has different specifications. The solution is that participants who successfully register help their friends to register, while still using the identity of the participant who cannot register. After successful registration, then login using their respective cellphones. After the implementation of this activity the youth felt happy, this was because they already had new skills in operating the SIPGAR application. According to the participants, SIPGAR is an application that is easy and accurate to measure a person's physical fitness, besides that the test can also be carried out anywhere and does not require a special place, the most important thing is that the distance reached is 1600 meters. So that the participants will be able to check their physical fitness regularly and independently easily. Another hope that the participants want is training on other applications to support their skills in operating applications regarding self-health checks independently.
\end{abstract}

Keywords: SIPGAR, Youth, River Flow

tetap bugar menjadi hal yang sangat penting. Begitu banyak cara yang bisa dilakukan untuk mencapai itu semua. Cara yang paling efektif guna menjaga kebugaran tubuh dimasa pandemi covid-19 saat ini yaitu dengan mematuhi protokol kesehatan serta ini, faktor kesehatan berupa menjaga agar tubuh 
membudayakan diri untuk beraktifitas berupa olahraga agar tubuh tetap dalam keadaan fit. Karena aktivitas fisik atau olahraga merupakan salah satu faktor yang dapat mempengaruhi kebugaran seseorang selain makanan bergizi (Harvianto et al., 2021) Begitu banyak sekali penelitian yang menjelaskan terkait dengan manfaat dari tubuh yang bugar, mulai dari dapat melakukan pekerjaan sehari-hari secara optimal, serta memiliki semangat hidup yang relatif tinggi (Candra Dewi et al., 2020).

Salah satu aktifitas olahraga yang dapat dilakukan pada masa pandemi covid-19 saat ini yaitu dengan berlari kecil atau jogging di ruang terbuka. Olahraga ini bisa dijadikan sebagai alternatif Bagi seseorang untuk menjaga tubuh agar tetap fit. Terlebih apabila dilakukan disaat tubuh bersentuhan langsung dengan sinar matahari. Sebab beberapa ahli mengatakan bahwa apabila seseorang terkena sinar matahari, hal itu sangat baik guna menjaga daya tahan tubuh atau imunitas (Zendrato, 2020). Selain itu juga bahwa pancaran sinar matahari ketubuh seseorang memiliki fungsi meningkatkan dan mempertahankan vitamin D (Setiati, 2008).

Berdasarkan observasi yang dilakukan, bahwa selama masa pandemi ini, terjadi penurunan aktivitas olahraga yang dilakukan oleh kalangan pemuda. Hal ini terjadi dikarenakan kurangnya edukasi kepada mereka perihal penting nya berolahraga disaat pandemi saat ini. Selain itu juga bahwa, terjadinya kekhawatiran yang terlalu berlebihan terhadap pandemi covid-19, sehingga banyak dikalangan pemuda yang enggan keluar rumah.

Terlebih bagi para pemuda di Daerah Aliran Sungai yang memang memiliki keterbatasan dalam hal fasilitas untuk berolahraga. Mereka lebih memilih berdiam diri dirumah bermain game online, daripada berolahraga diluar rumah guna menjaga tubuh agar tetap fit. Menurut (Alamsyah, D.A.N, Hestiningsih, R, Saraswati, 2017) para remaja atau pemuda memang sering sekali melupakan faktor kebugaran jasmani pada dirinya. Menurut (Furkan et al., 2021) berolahraga diluar rumah pada masa pandemi covid-19 bisa dilakukan asalkan tetap mematuhi protokol kesehatan, diantaranya tidak dilakukan secara berkelompok atau berkerumunan. Selain itu juga bahwa, para pemuda belum mendapatkan edukasi guna mengecek kebugaran jasmani mereka secara mandiri. Padahal sangat dianjurkan bagi seseorang mengecek kebugaran secara rutin. Cek kebugaran jasmani secara rutin, merupakan bagian dari tes kesehatan secara rutin untuk menghindari penyakit sedini mungkin (Furkan et al., 2021).

Guna memberikan solusi dari masalah yang ada tersebut, maka perlunya diadakan sebuah pelatihan bagi para pemuda DAS di Kota Palangka Raya. Dengan mengikuti pelatihan ini, para pemuda akan mengetahui betapa pentingnya melakukan olahraga disaat pandemi saat ini agar tubuh tetap bugar. Selain itu juga, para pemuda akan diberikan edukasi perihal melakukan aktivitas olahraga selama masa pandemi. Serta para pemuda akan diajarkan dalam penggunaan aplikasi SIPGAR. Sebuah aplikasi yang diterbitkan oleh Kementerian Kesehatan Republik Indonesia untuk mengecek kebugaran jasmani seseorang secara mandiri melalui android.

Dalam aplikasi SIPGAR ini para pemuda bisa melakukan konsultasi perihal kebugaran jasmaninya serta mendapatkan rekomendasi program olahraga yang bisa dilakukan sesuai dengan kondisi tubuh seseorang setelah melakukan tes melalui aplikasi SIPGAR.

Tujuan dari kegiatan ini yaitu para pemuda mendapatkan edukasi perihal kebugaran jasmani dan dapat melakukan tesnya secara mandiri. Manfaat dari kegiatan ini yaitu para pemuda mengetahui betapa pentingnya olahraga, serta panduan-panduan berolahraga dimasa pandemi covid-19. Selain itu juga dengan mengkuti pelatihan ini para pemuda dapat menggunakan aplikasi SIPGAR untuk mengecek kebugaran jasmani mereka secara mandiri.

\section{Metode}

Berdasarkan latar belakang masalah yang telah dijelaskan diatas, solusi yang kami berikan berupa pelatihan. Dimana pelatihan ini dilakukan selama 5 kali dibeberapa tempat di Kota Palangka Raya, dengan peserta yang berbeda-beda pula. Pelatihan pertama dilakukan di Kompleks Arena Pameran Temanggung Tilung pada hari Senin 13 September 2021 diikuti oleh 12 peserta, pelatihan 
kedua dilakukan di Kompleks GOR Indoor Palangka Raya Cilik Riwut KM 5 pada hari Selasa 14 September 2021 diikuti oleh 6 peserta, pelatihan ketiga dilakukan di Kompleks Kolam Renang Isen Mulang Palangka Raya pada hari Rabu 15 September 2021 diikuti oleh 7 peserta, pelatihan keempat dilakukan di Laboratorium Olahraga Fitness Center JUARA pada hari Kamis 16 September 2021 diikuti oleh 9 peserta, pada pelatihan kelima dilakukan di Kompleks Stadion Mantikei pada hari Jum'at 17 September 2021 diikuti oleh 8 peserta. Sehingga jumlah keseluruhan peserta yang mengikuti kegiatan ini berjumlah 42 orang.

Peserta merupakan pemuda yang memiliki usia 15-23 tahun, yang berdomisili di sekitar Daerah Aliran Sungai (DAS). Dalam pelatihan ini, peserta diberikan materi dasar tentang kebugaran jasmani, baik itu definisi, faktor-faktor yang mempengaruhi maupun komponen-komponen kebugaran jasmani. Selian itu juga para peserta diberikan materi tentang betapa pentingnya berolahraga, terutama dimasa pandemi covid-19 saat ini. Selanjutnya dijelaskan secara umum dari aplikasi SIPGAR yang telah diterbitkan oleh Kementerian Kesehatan Republik Indonesia. Kemudian dalam pelatihan ini juga peserta akan dipandu dalam menggunakan aplikasi SIPGAR. Selain dipandu untuk mengukur kebugaran jasmani dengan menggunakan SIPGAR, para peserta juga akan dipandu untuk menggunakan SIPGAR sesuai dengan item yang ditawarkan pada aplikasi tersebut. Diantaranya terdapat item perihal informasi kesehatan, data kebugaran jasmani, konsultasi kebugaran serta rekomendasi program aktivitas olahraga sesuai dengan hasil tes yang telah dilakukan. Selanjutnya peserta secara langsung diajak bersama-sama untuk melakukan tes guna mengukur kebugaran jasmaninya secara mandiri dengan aplikasi SIPGAR.

Setelah mengikuti pelatihan ini, para peserta mendapatkan edukasi tentang olahraga dan panduan dalam melakukannya selama masa pandemi covid19 ini. Selain itu juga bahwa dengan adanya pelatihan ini, para peserta dapat mengukur status kebugaran jasmani mereka secara mandiri dengan rutin melalui aplikasi SIPGAR. Serta dapat berkonsultasi perihal kebugaran dan akan mendapatkan program aktivitas olahraga dari aplikasi SIPGAR.

Diakhir kegiatan, disebar kuesinoer kepada para peserta, dengan tujuan untuk mengetahui seberapa pengaruh kegiatan ini bagi peserta. Sehingga dapat diketahui seberapa besar ketercapaian indikator keberhasilan kegiatan ini.

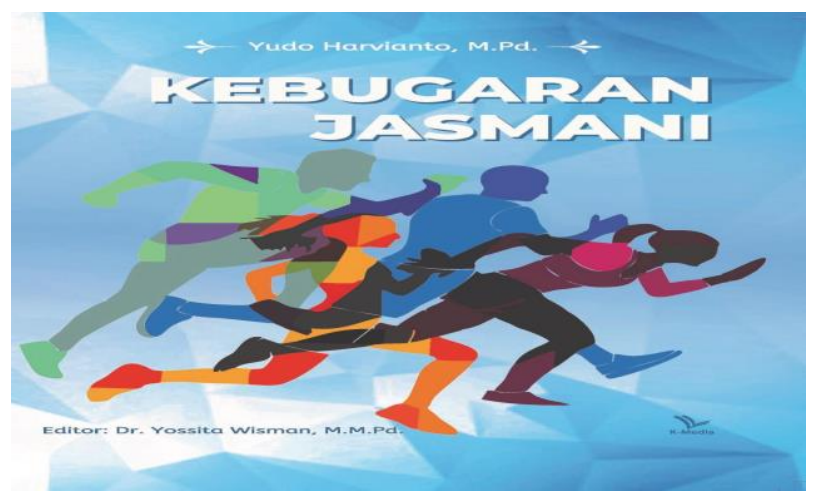

Gambar 1. Sampul Materi

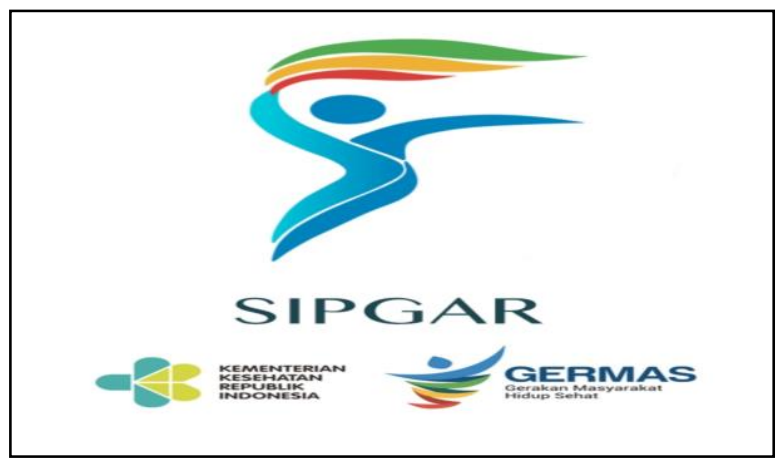

Gambar 2. Aplikasi SIPGAR

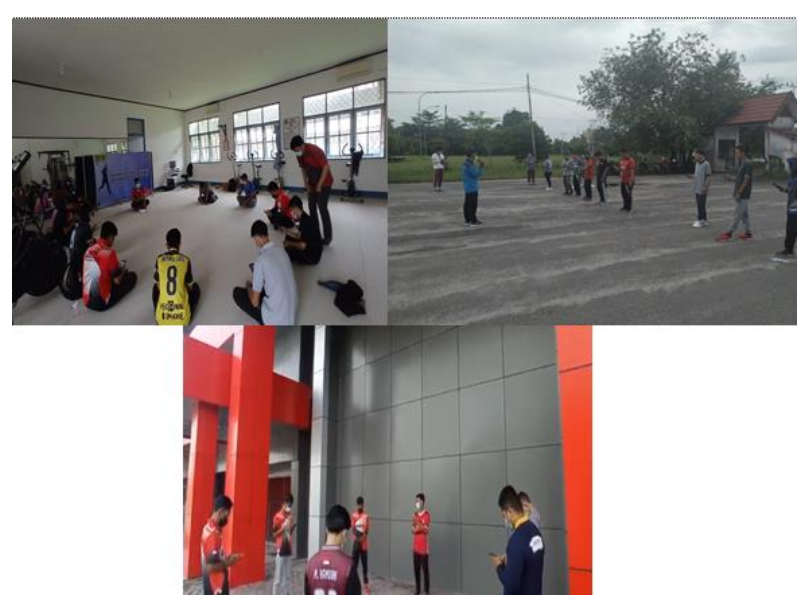

Gambar 3. Penyampaian Materi dan Sosialisasi SIPGAR 


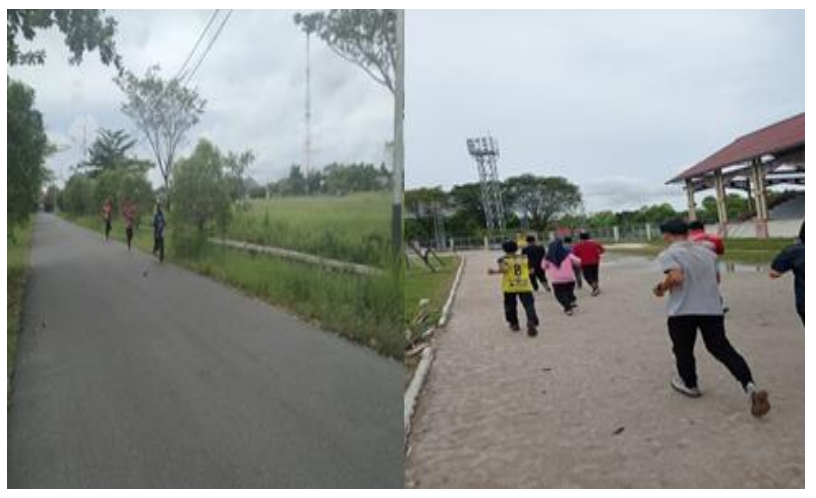

Gambar 4. Praktek Penggunaan Aplikasi SIPGAR

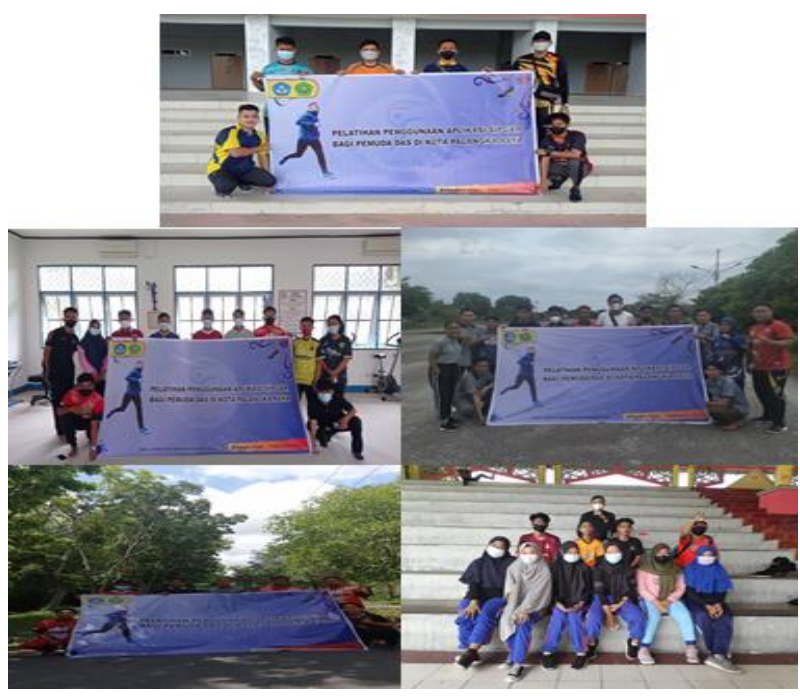

Gambar 5. Foto Bareng Seluruh Peserta

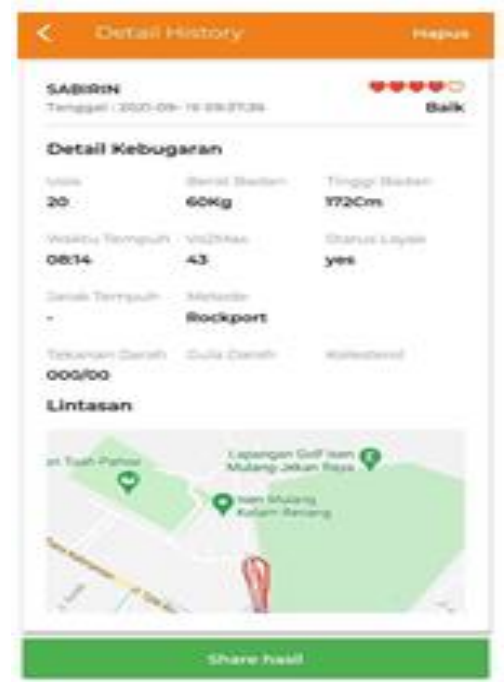

Gambar 6. Hasil Tes Peserta

\section{Hasil dan Pembahasan}

Kebugaran jasmani adalah kemampuan individu dalam melakukan aktivitas sehari-hari dengan mudah tanpa merasakan kelelahan yang terlalu berlebihan dan masih memiliki sisa tenaga untuk melaksanakan kegiatan selanjutnya (Harvianto, 2020). Apabila kita merenungi pengertian kebugaran jasmani diatas, maka kita akan memahami bahwa manusia sangatlah memerlukan tubuh yang bugar dalam kehidupan sehari-hari untuk melakukan segala macam kegiatan. Terlebih setiap manusia memiliki segala macam kegiatan yang berbeda-beda, sehingga kebutuhan kebugaran jasmaninya pun akan berbeda-beda. Bagi seseorang yang melakukan aktivitas sehari-hari berupa kegiatan ringan atau kecil, maka kebutuhan kebugaran jasmaninya yang dibutuhkan tidak terlalu besar, akan tetapi bagi seseorang yang melakukan aktivitas sehari-hari berupa kegiatan berat atau besar, maka kebutuhan kebugaran jasmani yang dibutuhkan besar pula. Perbedaan kebutuhan kebugaran jasmani ini terjadi karena aktivitas yang dilakukan berbeda.

Disaat seseorang tersebut melakukan aktivitas ringan, energi yang dibutuhkan untuk melakukan aktivitas tersebut tidak besar, namun dikala seseorang tersbut melakukan aktivitas yang berat atau besar, maka energi yang dibutuhkan untuk melakukan aktivitas tersebut juga besar. Sehingga pada hakikatnya bahwa kebugaran jasmani yang dimiliki oleh seseorang tersebut berfungsi sebagai penopang untuk melakukan aktivitas dalam kehidupan sehari-hari.

Oleh karena itu, hendaknya seseorang peduli terhadap kebugaran jasmani dirinya. Salah satu indikator kepedulian kita terhadap kebugaran jasmani yaitu menjaga pola makan dan minum yang bergizi dan seimbang, melakukan olahraga secara rutin, serta memperhatikan lingkungan sekitar agar tetap bersih dan sehat. Selain itu juga hendaknya seseorang secara rutin untuk mengecek kebugaran jasmaninya. Cek kebugaran jasmani secara rutin, merupakan bagian dari tes kesehatan secara rutin untuk menghindari penyakit sedini mungkin (Sukmana et al., 2020).

Berdasarkan hasil yang didapatkan dari kegiatan ini, terdapat beberapa permasalahan yang dialami oleh peserta diantaranya tidak semua peserta bisa melakukan download aplikasi pada 
play store dan registrasi akun. Hal ini dikarenakan pada masing-masing handphone yang dimiliki peserta memiliki spesifikasi yang berbeda-beda. Solusi yang dilakukan yaitu peserta yang berhasil registrasi menolong rekannya untuk mendaftar, dengan tetap menggunakan identitas peserta yang tidak bisa registrasi tersebut. Setelah registrasi sukses, barulah login dengan menggunakan handphone masing-masing.

Setelah terlaksananya kegiatan ini para pemuda merasa senang, hal ini dikarenakan mereka telah memiliki keterampilan baru dalam pengoperasian aplikasi SIPGAR. Menurut para peserta, SIPGAR merupakan sebuah aplikasi yang mudah dan akurat dalam mengukur kebugaran tubuh seseorang, selain itu pelaksanaan tesnya juga bisa dilakukan dimana saja dan tidak membutuhkan tempat khusus, yang terpenting jarak tempuh yang dicapai sejauh 1600 meter. Sehingga para peserta nantinya dapat melakukan pengecekan kebugaran jasmani secara rutin dan mandiri dengan mudah. Harapan lain yang diinginkan para peserta yaitu adanya pelatihan tentang aplikasi lainnya guna penunjang keterampilan mereka dalam pengoperasian aplikasi tentang pengecekan kesehatan diri secara mandiri.

\section{Kesimpulan}

Berdasarkan kegiatan pengabdian pada masyarakat yang telah dilakukan ini, dapat disimpulkan bahwa kegiatan pelatihan penggunaan aplikasi SIPGAR bagi pemuda DAS di kota Palangka Raya ini, dapat memberikan edukasi perihal pentingnya menjaga dan mengecek kebugaran jasmani secara rutin dan mandiri, serta pelatihan ini juga telah menambah keterampilan pemuda dalam mengoperasikan sebuah aplikasi perihal pengecekan kebugaran secara mandiri.

\section{Saran}

Diharapkan lebih banyak lagi pelatihanpelatihan yang dilakukan kepada para pemuda khususnya tentang pengoperasian aplikasi SIPGAR guna pengecekan kebugaran jasmani secara rutin dan mandiri.

\section{Ucapan Terima Kasih}

Penulis mengucapkan terima kasih kepada Dekan Fakultas Keguruan dan Ilmu Pendidikan Universitas Palangka Raya yang telah memberi dukungan baik secara moril maupun finansial terhadap pengabdian ini. Serta penulis mengucapkan terima kasih pula kepada mitra kami yaitu Musyawarah Guru Mata Pelajaran Pendidikan Jasmani, Olahraga dan Kesehatan Sekolah Menengah Kejuruan (MGMP PJOK SMK) Kota Palangka Raya yang telah berkenan bekerja sama sehingga kegiatan ini dapat terlaksana dengan baik dan sukses.

\section{Daftar Pustaka}

Alamsyah, D.A.N, Hestiningsih, R, Saraswati, L. . (2017). Faktor-Faktor Yang Berhubungan Dengan Kebugaran Jasmani Pada Remaja Siswa Kelas Xi Smk Negeri 11 Semarang. Jurnal Kesehatan Masyarakat (e-Journal), 5(3), 77-86.

Candra Dewi, N. K. A. T., Astra, I. K. B., \& Suwiwa, I. G. (2020). Motivasi Mahasiswa Prodi Pendidikan Jasmani Kesehatan Dan Rekreasi Fakultas Olahraga Dan Kesehatan Menjaga Kebugaran Jasmani Pada Masa Pandemi Covid-19. Jurnal Ilmu Keolahragaan Undiksha, 8(1). https://doi.org/10.23887/jiku.v8i1.29573

Furkan, Rusdin, \& Shandi, S. A. (2021). Menjaga Daya Tahan Tubuh Dengan Olahraga Saat Pandemi Corona Covid-19. Jurnal Ilmu Sosial Dan Pendidikan, 5(1), 424-430. http://ejournal.mandalanursa.org/index.php/JISIP/ article/view/1748

Harvianto, Y. (2020). Kebugaran Jasmani (Y. Wisman (ed.); 1st ed.). K-Media.

Harvianto, Y., Wire, N., \& Sakti, P. (2021). Sosialisasi Pendampingan Asupan Gizi Atlet Muda di Kota Palangka Raya pada. Jurnal Pengabdian Magister Pendidikan IPA, 4(3), 10-14. https://doi.org/https://doi.org/10.29303/jpmpi.v3i 2.851

Setiati, S. (2008). Pengaruh Pajanan Sinar Ultraviolet B Bersumber dari Sinar Matahari terhadap Konsentrasi Vitamin D (25(OH)D) dan Hormon Paratiroit pada Perempuan Usia Lanjut Indonesia. Kesmas: National Public Health Journal, 2(4), 147. https://doi.org/10.21109/kesmas.v2i4.257

Sukmana, D. J., Hardani, H., \& Irawansyah, I. (2020). Pemeriksaan Kesehatan Gratis sebagai Upaya 
Peningkatan Kesadaran Masyarakat terhadap Deteksi Dini Penyakit Tidak Menular. Indonesian

Journal of Community Services, 2(1). https://doi.org/10.30659/ijocs.2.1.19-26

Zendrato, W. (2020). Gerakan Mencegah Daripada Mengobati Terhadap Pandemi Covid-19. Jurnal Education and Development, 8(2), 242-248. 